\title{
The effects of diets containing raw soya-bean flour on the vitamin $B_{12}$ status of rats
}

\author{
By D. L. WILLIAMS AND G. H. SPRAY \\ Nuffield Department of Clinical Medicine, \\ Radcliffe Infirmary, Oxford, $\mathrm{OX}_{2} 6 \mathrm{HE}$ \\ (Received ${ }_{25}$ November 1971 - Revised 15 August 1972)
}

\begin{abstract}
I. There were statistically-significant relationships between the concentrations of vitamin $\mathbf{B}_{12}$ in the livers of rats and their urinary excretion of methylmalonic acid, both before and after the intraperitoneal injection of sodium propionate.

2. The effects of diets based on raw and heated soya-bean flour (SBF) on the growth rates, urinary excretion of methylmalonate and hepatic vitamin $B_{12}$ were compared in normal and vitamin $\mathrm{B}_{12}$-depleted rats.

3. When female weanling vitamin $B_{12}$-deficient rats were put on to the raw SBF diet they lost weight and became moribund after 3 weeks, even when the diet was supplemented with vitamin $\mathrm{B}_{12}$. Male adult vitamin $\mathrm{B}_{12}$-deficient rats lost weight but showed no other signs of severe vitamin $B_{12}$ deficiency.

4. Stock weanling male rats were fed on raw SBF diets with or without added vitamin $B_{12}$. The diets were given alone and supplemented with either methionine or a mixture of methionine, valine, threonine and tyrosine. The rats still did not grow as well as those fed on diets containing heated SBF. However, there was some evidence of increased methylmalonate excretion and lower hepatic concentrations of vitamin $B_{12}$ in the rats fed on the raw SBF diets.
\end{abstract}

Rats are very difficult to deplete of vitamin $B_{12}$ (Williams, Spray, Newman \& O'Brien, 1969), partly because they carry over reserves of the vitamin from their dams and partly because some vitamin $B_{12}$ is synthesized in their intestines and is absorbed as the result of coprophagy. Nevertheless, because of their low cost, ready availability and ease of handling, rats are convenient laboratory animals and therefore efforts continue to be made to induce in them a severe deficiency of vitamin $B_{12}$.

Soya-bean flour (SBF), being comparatively rich in protein and free from vitamin $B_{12}$, is convenient as the source of protein in vitamin $B_{12}$-deficient diets. It has been suggested (e.g. Frölich, 1954; Edelstein \& Guggenheim, 1970) that dicts based on raw or under-heated SBF increase the requirements for vitamin $B_{12}$. We have therefore studied the effects of such diets on the vitamin $B_{12}$ status of rats. We attempted first to assess the value of determinations of the urinary excretion of methylmalonic acid under various conditions as indices of vitamin $B_{12}$ status, by studying the correlation between the excretion of methylmalonate and hepatic vitamin $\mathrm{B}_{\mathbf{1 2}}$.

\section{EXPERIMENTAL}

Animals and their management. Stock weanling male and female albino rats of the Wistar strain were obtained from Allington Farm, Porton Down, Salisbury, Wilts. Some were reared on rat cake (modified diet $4 \mathrm{I}$ B, Herbert C. Styles (Bewdley) Ltd) and were mated. After mating, the females were fed throughout on the vitamin 
$\mathrm{B}_{12}$-deficient, heated SBF diet. Some of the resulting young of both sexes were reared on the vitamin $\mathrm{B}_{12}$-deficient diet and are referred to as 'vitamin $\mathrm{B}_{12}$-deficient' rats.

For the dietary experiments the rats were housed in groups in plastic cages with stainless-steel tops and bottoms and were weighed weekly. While urine was collected all rats were housed individually in glass metabolism cages with devices for separating urine and faeces. Food was not allowed but water was supplied ad lib.

Diets. The diet based on heated SBF contained $(\mathrm{g} / \mathrm{kg}$ ): 600 SBF (Soyolk; Soya Foods Ltd, London $\mathrm{EC}_{3}$ ), 205 sucrose, II lactose, 5 choline dihydrogen citrate, 65 mineral salts and I heated SBF in the raw SBF diets. In those experiments where methionine alone, or valine, threonine, tyrosine and methionine were added, the corresponding amounts of raw SBF were omitted. Cyanocobalamin $(15 \mu \mathrm{g} / \mathrm{kg}$ diet) was added to the vitamin $B_{12}$-supplemented diets.

Expt 1. Methylmalonate excretion and liver vitamin $B_{12}$. Both male and female vitamin $B_{12}$-deficient rats aged between Io and 16 weeks, that had been on the heated $\mathrm{SBF}$ vitamin $\mathrm{B}_{12}$-deficient diet throughout, were studied. The animals were different from those used for the dietary tests. Urine was collected from each rat under three conditions: ( $\mathrm{I}$ ) during starvation for $24 \mathrm{~h}$ after receiving food $a d l i b . ;(2)$ as in I with the rats receiving I mmol sodium propionate $/ \mathrm{I} 50 \mathrm{~g}$ body-weight by intraperitoneal injection at the start of the collection; (3) during the second $24 \mathrm{~h}$ of a period of starvation for $48 \mathrm{~h}$, the animals receiving propionate as in 2 at the start of the collection. After the three collections of urine, the rats were killed, the livers were removed and the concentration of vitamin $B_{12}$ determined. Results obtained under condition 2 are included for the male rats fed on the heated SBF diets both with and without vitamin $\mathrm{B}_{12}$ in the dietary experiments with stock rats (Expt 3 ).

Expt 2. Effects of raw SBF diets in vitamin $B_{12}$-deficient rats. Twenty-four female vitamin $B_{12}$-deficient weanling rats were assigned randomly to three groups and fed on either the raw SBF vitamin $B_{12}$-deficient diet, the same diet supplemented with vitamin $B_{12}$, or the heated $\mathrm{SBF}$ diet supplemented with vitamin $B_{12}$. Urine was not collected from these rats.

In the next experiment, two groups of eight adult, male, vitamin $B_{12}$-deficient rats were fed on the vitamin $B_{12}$-deficient raw or heated SBF diets. Urine was collected at suitable times.

Expt 3. Effects of raw SBF diets in stock (vitamin $B_{12}$-replete) rats. Groups of eight weanling rats were fed either on the raw or the heated SBF diets with or without vitamin $B_{12}$, or on raw SBF diets supplemented with ro $\mathrm{g}$ L-methionine $/ \mathrm{kg}$ with or without vitamin $B_{12}$. Urine was collected every two weeks for the determination of methylmalonic acid, which was measured under condition 2 . The rats were killed after 12 weeks, the livers were removed and the concentrations of vitamin $B_{12}$ determined.

In a final attempt to overcome the growth-depressing effect of raw SBF, the diets were supplemented with valine, threonine, tyrosine and methionine (Borchers, 1959). Groups of eight male weanling rats were fed either on raw or heated SBF diets with or without vitamin $B_{12}$, or on raw SBF diets with or without vitamin $B_{12}$ and supple- 
Table I. Expt I. Relationship between the urinary excretion of methylmalonate by rats fed on diets containing heated soya-bean flour and their hepatic vitamin $B_{12}$

(The excretion of methylmalonate was determined under three conditions; sce Experimental for details. The rats were then killed and the concentration of vitamin $B_{12}$ in their livers measured. Mean values with their standard errors; number of observations in parentheses)

\begin{tabular}{|c|c|c|c|}
\hline & Condition I & $\begin{array}{l}\text { Condition } 2 \\
\text { Male rats }\end{array}$ & Condition 3 \\
\hline $\begin{array}{l}\text { Urinary methylmalonate }(x) \\
(\mathrm{mg} / \mathrm{kg} \text { body-wt per } \mathrm{d}) \\
\text { Liver vitamin } \mathrm{B}_{12} *(y)\end{array}$ & $216 \cdot 6 \pm 29 \cdot 3(3 t)$ & $423 \cdot 8 \pm 5 I \cdot I(5 I) \dagger$ & $560.9 \pm 57 \cdot 6(32)$ \\
\hline $\begin{array}{l}\text { (ng/g wet tissue) } \\
\text { Correlation coefficient }\end{array}$ & $16 \cdot 77 \pm 1 \cdot 34(3 \mathrm{I})$ & $25.80 \pm 2.99(5 x) \dagger$ & $16 \cdot 53 \pm I \cdot 33(32)$ \\
\hline$P^{\left(\log _{10} x v \cdot \log _{10} y\right)}$ & $\begin{array}{l}-0.522 \\
<0.01\end{array}$ & $\begin{array}{l}-0.767 \\
<0.001\end{array}$ & $\begin{array}{l}-0.686 \\
<0.001\end{array}$ \\
\hline & & Female rats & \\
\hline $\begin{array}{l}\text { Lrinary methylmalonate }(x) \\
(\mathrm{mg} / \mathrm{kg} \text { body-wt per } \mathrm{d}) \\
\text { Liver vitamin } \mathrm{B}_{12}{ }^{*}(y)\end{array}$ & $54 \cdot 8 \pm 7 \cdot 7(30)$ & $197 \cdot 6 \pm 25 \cdot 7(28)$ & $158 \cdot 8 \pm 18 \cdot 2(3 \mathrm{I})$ \\
\hline $\begin{array}{l}\text { (ng/g wet tissue) } \\
\text { Correlation coefficient }\end{array}$ & $34.53 \pm 4.88(30)$ & $34 \cdot 64 \pm 5 \cdot 15(28)$ & $35 \cdot 23 \pm 4 \cdot 77(31)$ \\
\hline$P^{\left(\log _{10} x v \cdot \log _{10} y\right)}$ & $\begin{array}{l}-0.483 \\
<0.01\end{array}$ & $\begin{array}{l}-0.794 \\
<0.001\end{array}$ & $\begin{array}{l}-0.568 \\
<0.001\end{array}$ \\
\hline
\end{tabular}

* The mean values for vitamin $B_{12}$ differ under each condition because results for methylmalonate were not obtained for all rats by each method.

$\uparrow$ Values for stock rats (Expt 3 ) included.

mented with $2 \mathrm{~g}$ L-valine, $6 \mathrm{~g}$ L-methionine, $6 \mathrm{~g}$ DL-threonine and $6 \mathrm{~g}$ L-tyrosine per $\mathrm{kg}$. Urine was collected at fortnightly intervals. After $\mathrm{I} 2$ weeks the rats were killed, the livers were removed and the concentrations of vitamin $B_{12}$ were determined.

Other methods. Vitamin $\mathrm{B}_{12}$ in liver and methylmalonic acid in urine were measured as described previously (Williams et al. 1969).

\section{RESULTS}

\section{Urinary excretion of methylmalonate and the concentration of vitamin $B_{12}$ in liver}

The results for males and females appeared to belong to different populations and the results for the sexes were therefore analysed separately. Significant correlations were found between the concentration of vitamin $B_{12}$ in the livers and the excretion of methylmalonate determined under all three conditions (Table $\mathrm{r}$ ). The logarithms of the values gave the best correlations and the results obtained under condition 2 are shown in Fig. I.

\section{Effects of diets containing raw $S B F$}

Vitamin $B_{12}$-deficient rats. The growth of the weanling rats receiving the raw SBF diets was severely inhibited and they became moribund after 3 weeks. Those fed on the raw $\mathrm{SBF}$ vitamin $\mathrm{B}_{12}$-deficient diet lost on average $8.8 \mathrm{~g}$ in the 3 weeks; those fed on the raw SBF vitamin $B_{12}$-supplemented diet lost $3 \cdot 7 \mathrm{~g}$, whereas controls given the heated SBF diet containing vitamin $\mathrm{B}_{12}$ gained $5^{8} \mathrm{~g}$. All the experimental rats were 


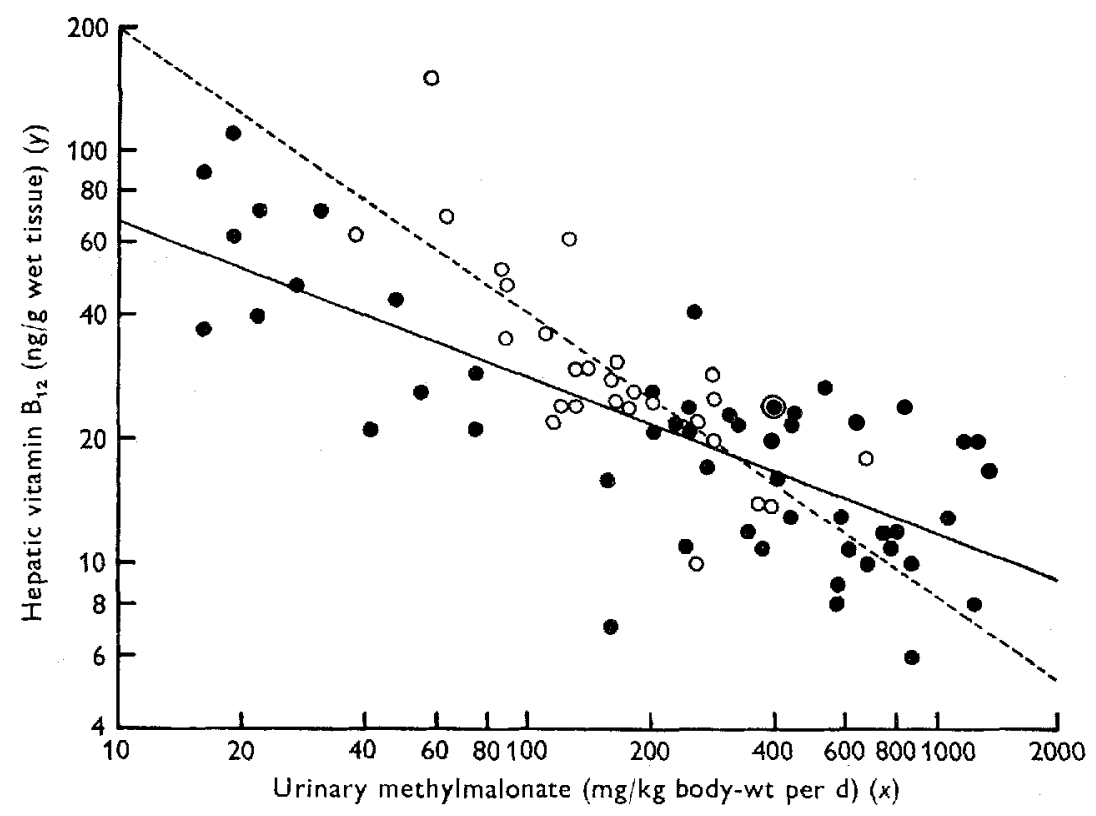

Fig. I. Logarithmic relationship between the urinary excretion of methylmalonic acid $(x)$ and the concentration of vitamin $B_{12}$ in the livers $(y)$ in male $(O)$ and female $(O)$ rats fed on heated soya-bean flour diets. Urine was collected during $24 \mathrm{~h}$ of starvation and the rats were given I mmol sodium propionate $/ 150 \mathrm{~g}$ body-weight at the start of the collection. The calculated regression lines are shown (in terms of $\log _{10}$, for males $y=1 \cdot 8_{3}-0.38 x$, — ; for females $y=2 \cdot 30-0.69 x,----)$.

then fed on the corresponding heated SBF diets and they grew almost to the same size as their controls. Eight weeks after changing the diet the mean weight increases since weaning were 98 , II 2 and $I \mathrm{I} 9 \mathrm{~g}$ respectively for the groups fed initially on the raw SBF vitamin $B_{12}$-deficient, raw $\mathrm{SBF}$ vitamin $\mathrm{B}_{12}$-supplemented and heated $\mathrm{SBF}$ vitamin $B_{12}$-supplemented diets.

The adult rats on the raw $S B F$ vitamin $B_{12}$-deficient diet lost a mean of $18 \mathrm{~g}$ during the first 3 weeks, whereas those on the heated SBF deficient diet gained a mean of $28 \mathrm{~g}$. The results for methylmalonate excretion, not recorded here, suggested that there was little or no difference in the vitamin $B_{12}$ status of the animals fed on the raw SBF and the heated SBF diets.

Stock rats. Supplementing the raw SBF diets with methionine partly overcame the inhibition of growth, particularly if vitamin $B_{12}$ was also included (Table 2). In this table and in Table 3 , mean values only are given; rigorous statistical treatment of the results is impossible because the rats in a group were housed in the same cage and there may have been lack of replication between cages. The rats fed on the vitamin $\mathrm{B}_{12}$-deficient raw SBF diets showed progressively increasing excretion of methylmalonate after injection of propionate up to 8 or io weeks (Table 2). Addition of methionine did not seem to affect the excretion until week 10, when it may have depressed the values. The rats fed on the heated SBF vitamin $B_{12}$-deficient diet excreted less methylmalonate throughout. The mean concentrations of vitamin $B_{12}$ 
Table 2. Expt 3. Weight gains, urinary excretion of methylmalonate (under condition 2, see Experimental) and hepatic concentration of vitamin $B_{12}$ in stock rats fed on vitamin $B_{12}$-deficient and vitamin $B_{12}$-supplemented raw or heated soya-bean flour (SBF) diets. The raw SBF diets were given either alone or supplemented with methionine

(Mean values for eight rats per treatment)

\begin{tabular}{|c|c|c|c|c|c|c|c|}
\hline Source of protein & $\cdots$ & $\operatorname{Rav}$ & & & $\begin{array}{l}B F \\
\text { nine }\end{array}$ & \multicolumn{2}{|c|}{ Heated SBF } \\
\hline Vitamin $\mathbf{B}_{1 \mathbf{2}}$ & $\cdots$ & - & + & - & + & - & + \\
\hline \multicolumn{8}{|c|}{ Weight gain (g) } \\
\hline $\begin{array}{ll}\text { Week } & 4 \\
& 8\end{array}$ & & $\begin{array}{l}46(7)^{*} \\
68(6)\end{array}$ & $\begin{array}{l}46 \\
70\end{array}$ & $\begin{array}{r}95 \\
142\end{array}$ & $\begin{array}{l}100 \\
199\end{array}$ & $\begin{array}{l}133 \\
227(5)\end{array}$ & $\begin{array}{l}123 \\
254\end{array}$ \\
\hline 12 & & $99(4)$ & 131 & I 37 & $236(7)$ & $264(5)$ & 330 \\
\hline
\end{tabular}

Urinary methylmalonate $(\mathrm{mg} / \mathrm{kg}$ body-wt per $\mathrm{d})$

\begin{tabular}{|c|c|c|c|c|c|c|c|}
\hline Week & 4 & 150 & 50 & 200 & 60 & 70 & 40 \\
\hline & 6 & 320 & 50 & 240 & 60 & 80 & 50 \\
\hline & 8 & 530 & 60 & 580 & 30 & I IO & 20 \\
\hline & IO & 620 & 一 & 480 & - & $13^{\circ}$ & - \\
\hline & I 2 & 410 & 40 & 290 & 30 & $17^{\circ}$ & 20 \\
\hline
\end{tabular}

Week I 2

Vitamin $\mathrm{B}_{12}$ (ng/g liver)

* Numbers in parentheses refer to the number of survivors when it is less than the original number of eight per treatment.

Table 3. Expt 3. Weight gains, urinary excretion of methylmalonate (under condition 2, see Experimental) and hepatic concentration of vitamin $B_{1.2}$ in stock rats fed on vitamin $B_{12}$-deficient and vitamin $B_{12}$-supplemented raw or heated soya-bean flour $(S B F)$ diets. The raw SBF diets were given either alone or supplemented with methionine, valine, threonine and tyrosine.

(Mean values for eight rats per treatment)

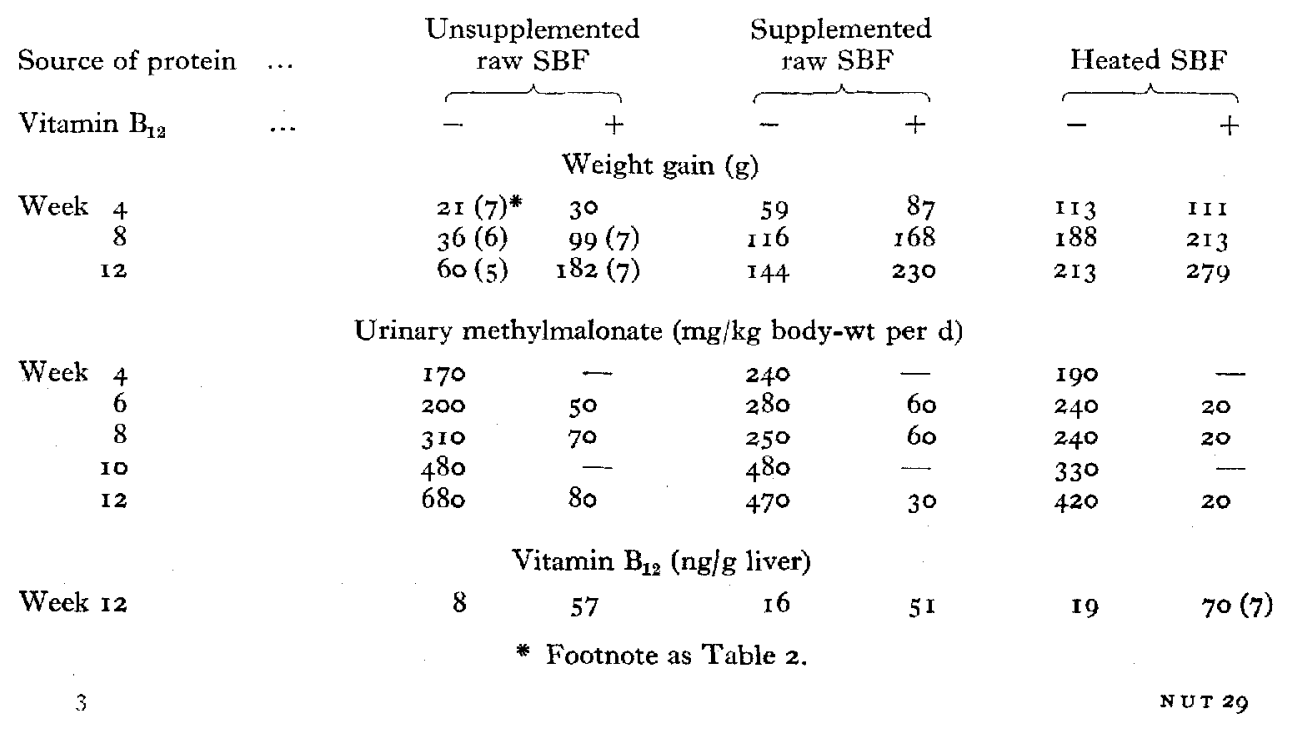


in the livers of the groups receiving the raw $\mathrm{SBF}$ vitamin $\mathrm{B}_{12}$-deficient diets were lower than those that had had the heated SBF-deficient diet (Table 2).

In the final experiment the rats fed on the raw SBF diets again did not grow as well as those fed on the corresponding heated SBF diets (Table 3). The excretion of methylmalonate tended to increase with time on all the vitamin $B_{12}$-deficient diets, though after week 8 the rats receiving the raw $S B F$ vitamin $B_{12}$-deficient diets tended to excrete more than those on heated SBF. At week I2 those fed on the raw SBFdeficient diet without added amino acids excreted most methylmalonate and had the lowest hepatic vitamin $\mathbf{B}_{12}$ concentration.

In agreement with our previous results with female stock weanling rats (Williams et al. 1969), there were no differences in weight gains between the male stock rats fed on the heated SBF vitamin $B_{12}$-deficient and supplemented diets for the first 4 weeks. Later, the animals receiving the deficient diet grew more slowly than those on the supplemented diet. This difference may have been due to the faster growth rate and larger ultimate size attained by male rats.

\section{DISCUSSION}

Relationship between methylmalonate excretion and liver vitamin $B_{12}$

Measurement of the urinary excretion of methylmalonic acid has been widely used clinically and experimentally in attempts to assess vitamin $B_{12}$ status. Cox \& White (1962) stated that there was no proportional relationship between subnormal serum vitamin $\mathrm{B}_{12}$ concentration and the excretion of methylmalonic acid, but Brozovic, Hoffbrand, Dimitriadou \& Mollin ( 1967 ) reported a moderately good correlation between these measurements. Reed \& Tarver (1970) reported some correlation between urinary excretion of methylmalonate and the activity of methylmalonyl-CoA mutase $(E C 5 \cdot 4.99 .2)$ in rat liver.

We previously used rats starved for $24 \mathrm{~h}$ before injection of test substances, since elimination of endogenous methylmalonate excretion made it simpler to interpret the results (Williams et al. 1969). The present results show that the excretion of methylmalonate both before and after doses of propionate related to body-weight gave some correlation with concentrations of vitamin $\mathrm{B}_{12}$ in liver. However, the correlations are only good enough for approximate estimates of concentrations of vitamin $B_{12}$ in the tissues to be made from measurements of the excretion of methylmalonate.

\section{Effects of diets containing raw $S B F$}

The attempt to induce a severe deficiency of vitamin $B_{12}$ in weanling rats bred from mothers fed on the vitamin $\mathrm{B}_{12}$-deficient diet since mating was abandoned owing to the severe inhibition of growth during the first 3 weeks. The results of this experiment, compared with those with stock rats, suggest that depletion of vitamin $B_{12}$ increases the inhibition of growth due to raw SBF diets. The attempt to induce a severe deficiency in adults was no more successful as judged by the excretion of methylmalonate.

In agreement with the findings of Edelstein \& Guggenheim (1970), the growth of 
rats fed on raw SBF diets was depressed. The addition of methionine did not restore growth to the levels found in rats fed on heated SBF diets. However, our results for the excretion of methylmalonate are not in agreement with those of Edelstein \& Guggenheim (1970). Methionine seems to have had no effect up to 8 weeks on the excretion of methylmalonate by rats fed on raw SBF diets. After ro and 12 weeks it apparently depressed the excretion (Table 2), but the effect was not as marked as that observed by Edelstein \& Guggenheim (1970).

Supplementing the raw SBF diet with the mixture of amino acids only partly overcame the inhibition of growth, and had no consistent effect on the excretion of methylmalonate. In this experiment the rats fed on the heated $\mathrm{SBF}$ vitamin $\mathrm{B}_{\mathbf{1 2}^{-}}$ deficient diet also excreted large amounts of methylmalonate, so that there was little or no evidence that raw SBF diets enhanced vitamin $B_{12}$ deficiency as judged by methylmalonate excretion. However, the concentrations of vitamin $\mathrm{B}_{12}$ in the livers of the rats fed on the raw $\mathrm{SBF}$ vitamin $\mathrm{B}_{12}$-deficient diet were lower than those in the other two groups.

Raw SBF is well-known to contain inhibitors of trypsin and other growth-depressing substances. Edelstein \& Guggenheim (1970) reviewed the evidence that its inclusion in diets may increase the excretion of sulphur-containing amino acids by the pancreas. Therefore, these diets may increase the animals' needs for vitamin $B_{12}$ because of the greater demand for amino acids. Supplying extra amino acids only partly overcomes this demand.

We conclude that although feeding rats on diets containing raw SBF renders them more deficient on the basis of lower concentrations of vitamin $B_{12}$ in the liver, it has only a small and variable effect on their methylmalonate excretion. Because of the toxic factors present in the raw SBF, which seriously influence the metabolism and general health of the animals and depress their growth, the deficiency of vitamin $B_{12}$ is not uncomplicated, so that these rats are not suitable for fundamental studies of the metabolic consequences of vitamin $B_{12}$ deficiency.

We acknowledge, with thanks, grants from the Medical Research Council and the Wellcome Trust, by which this work was supported in part. We thank Miss Susan Parker for technical assistance.

\section{REFERENCES}

Borchers, R. (1959). Fedn Proc. Fedn Am. Socs exp. Biol. 18, 5 I7.

Brozovic, M., Hoffbrand, A. V., Dimitriadou, A. \& Mollin, D. L. (1967). Br. \%. Haemat. 13, I021.

Cox, E. V. \& White, A. M. (1962). Lancet ii, 853 .

Edelstein, S. \& Guggenheim, K. (1970). Br. F. Nutr. 24, 735 .

Frölich, A. (1954). Nature, Lond. 173, т32.

Reed, E. B. \& Tarver, H. (1970). F. Nutr. roo, 935.

Williams, D. L., Spray, G. H., Newman, G. E. \& O'Brien, J. R. P. (1969). Br. J. Nutr. 23, 343. 